\title{
SCREENING FOR DIABETIC RETINOPATHY - A TWELVE-MONTH REVIEW
}

\author{
Tomaž Gračner ${ }^{1,2}$ \\ ${ }^{1}$ Maribor University Clinical Centre, Department of Ophthalmology, Maribor, Slovenia; \\ ${ }^{2}$ University of Maribor, Faculty of Medicine, Maribor, Slovenia
}

\begin{abstract}
SUMMARY - The purpose is to provide a twelve-month database review of screening for diabetic retinopathy (DR). A total of 1428 diabetes mellitus (DM) patients screened in 2017 were analyzed in a retrospective study. Retinal photographs were reviewed by an ophthalmologist for the presence and stage of DR, as well as for additional nondiabetic findings. The following grading categories of DR were used: without DR, mild non-proliferative DR (NPDR), moderate NPDR, severe nonproliferative NPDR, proliferative DR (PDR), clinically significant macular edema (CSME) and ungradable finding. Severe NPDR, PDR and CSME were classified as vision-threatening DR. Out of $1428 \mathrm{DM}$ patients, 27 were diagnosed with type $1 \mathrm{DM}$ and 1401 with type $2 \mathrm{DM}, 353$ of them had newly diagnosed type $2 \mathrm{DM}$. Without DR category was recorded in $85.2 \%$ of all eyes screened, $2.8 \%$ were ungradable, and $12 \%$ showed varying stages of DR. Vision-threatening DR was found in $2.8 \%$ and additional nondiabetic findings in $5.2 \%$ of all screened eyes. In the group of newly diagnosed type 2 DM, $92.5 \%$ of screened eyes were without DR, 3.1\% were ungradable and $4.3 \%$ showed varying stages of DR. In the group of newly diagnosed type $2 \mathrm{DM}$, vision-threatening DR was recorded in $0.1 \%$ and additional nondiabetic finding in $5.7 \%$ of the eyes screened. In conclusion, a small proportion of screened DM patients with detected DR had vision-threatening DR.
\end{abstract}

Key words: Diabetes mellitus; Diabetic retinopathy; Screening; Proliferative retinopathy; Maculopathy

\section{Introduction}

Diabetes mellitus (DM) is one of the world's fastest growing chronic diseases and according to the World Health Organization, the global prevalence of DM is predicted to increase dramatically in the coming decades, from an estimated 382 million in 2013 to 592 million by $2035^{1,2}$. Diabetic retinopathy (DR) is the most common microvascular complication of $\mathrm{DM}^{3}$. Consequently, DR is the leading cause of blindness in working age individuals in industrialized countries and the fourth cause of blindness in developing countries in people of all age groups ${ }^{4,5}$. Therefore, screening for DR is important because early, timely

Correspondence to: Assoc. Prof. Tomaž Gračner, $M D, P b D$, Maribor University Clinical Centre, Department of Ophthalmology, Ljubljanska 5, 2000 Maribor, Slovenia

E-mail: gtomaz.dr@siol.net

Received July 11, 2018, accepted January 7, 2019 and regular retinal examinations in patients with DM are crucial to detect $\mathrm{DR}$ stages that require prompt treatment of vision-threatening DR and thus enable prevention of DM related visual impairment ${ }^{6-9}$. DM patients who do not attend DR screenings are at an increased risk of developing vision-threatening $\mathrm{DR}^{10}$. In Europe, $50 \%$ of type $1 \mathrm{DM}$ patients without DR at baseline were shown to develop DR within 5 to 7 years, and $9 \%$ of those with mild non-proliferative DR (mild NPDR) would develop proliferative DR (PDR) by 5 years ${ }^{11}$. In the UK, the 5 -year cumulative DR incidence in type $2 \mathrm{DM}$ patients was $4 \%$, rising to $16.4 \%$ after 10-year follow-up, from no retinopathy to pre$\mathrm{PDR}^{12}$. Most guidelines recommend annual screening for DR, so patients with type $1 \mathrm{DM}$ are recommended to initiate screening 3-5 years after diagnosis and then yearly thereafter, whereas patients with type $2 \mathrm{DM}$ are recommended to initiate screening at the time of diagnosis and then yearly thereafter ${ }^{13-16}$. Screening for eye 
disease caused by DM with the current annual examination model is cost-effective since it saves money by reducing vision loss ${ }^{15,17}$.

In the National Program for Controlling Diabetes Mellitus 2010-2020, launched by the Ministry of Health of the Republic of Slovenia, the execution of systematic examinations of DM patients and screening for DR is planned. The Ministry of Health of the Republic of Slovenia has decided that screening for DR should be performed at eight Diabetic Retinopathy Screening Service Centres, which are located in eight towns all over Slovenia. One of these Diabetic Retinopathy Screening Service Centres is at the Department of Ophthalmology, Maribor University Clinical Centre in Maribor, where screening for DR has been performed since November 2015. The purpose of this study was to provide a twelve-month review of the results of screening for DR, with focus on the diagnosis made, referral rates and follow-up recommendations in all DM patients screened, the subgroup of type $1 \mathrm{DM}$ patients and subgroup of newly diagnosed type $2 \mathrm{DM}$ patients.

\section{Patients and Methods}

This twelve-month retrospective database review conducted at Diabetic Retinopathy Screening Service Centre at Department of Ophthalmology, Maribor University Clinical Centre, Maribor, Slovenia, included all DM patients screened between January and December 2017. All patients underwent a standardized protocol. Patient self-reported data on referral physician, age, gender, type of diabetes, duration of DM, DM therapy, and past ocular and general medical history were recorded. All procedures performed in this study were in accordance with ethical standards of the institutional and national Research Committees, 1964 Helsinki Declaration and its later amendments or comparable ethical standards. Informed consent was obtained from all patients included in the study.

Presenting visual acuity (VA) at distance was recorded for each eye before dilating pupils for fundus photography. VA was measured with the patient wearing their 'walk-in' optical correction (i.e. spectacles or contact lenses) using decimal equivalents of Snellen chart. If the patient was unable to read the largest letter at $5 \mathrm{~m}$ with subjective refraction, then VA was re- corded as counting fingers, hand movements, light perception or no light perception.

At least two $45^{\circ}$ wide-angle field digital retinal photography images per eye were taken by an experienced ophthalmic technician. Mydriatic 2-field digital photography, one centered on the optic disc and the other on the macula was carried out in all DM patients attending the screening. Images were reviewed for the presence and stage of DR or clinically significant macular edema (CSME) by an ophthalmologist. Levels of DR or CSME were defined according to definitions used in the Early Treatment Diabetic Retinopathy Study (ETDRS) ${ }^{9}$. Mild NPDR was defined as the presence of one or more microaneurysms only. Moderate NPDR was defined as the presence of microaneurysms and blot hemorrhages with or without any additional lesions such as hard exudates, cotton wool spots, intraretinal microvascular abnormalities (IRMA), venous beading, but less pronounced than in severe NPDR. Severe NPDR was defined as the presence any of the following (4:2:1): extensive $(>20)$ intraretinal hemorrhages in each of 4 quadrants; definitive venous beading in $2+$ quadrants or more; prominent IRMA in 1+ quadrant or more, and no signs of PDR. The presence of PDR was determined by assessment of retinal neovascularizations, growth of abnormal vessels or/and preretinal or vitreous hemorrhage. CSME was defined as thickening of the retina at or within $500 \mu \mathrm{m}$ of the center of the macula; hard exudates at or within the center $500 \mu \mathrm{m}$ from the center of macula, if associated with thickening of retina.

The following grading categories of DR were used: without DR, mild NPDR, moderate NPDR, severe NPDR, PDR, CSME, and ungradable. Retinal photographs were considered ungradable if the retina could not be visualized appropriately, i.e. when retinal vessels were not visible within 1 disc diameter of the center of the fovea, and fine vessels were not visible across the surface of the optic disc.

Additional nondiabetic clinical findings on retinal photographs, such as age-related macular degeneration, glaucoma suspect optic neuropathy, cataract, choroidal nevus, or other nondiabetic causes of retinopathy (retinal vein occlusion, branch retinal vein occlusion) were also recorded.

The recommended follow-up time for patients without DR was 12 months, for patients with mild NPDR 8-10 months, and for those with moderate 
NPDR 6-8 months. Patients graded as severe NPDR, PDR or CSME were classified as having visionthreatening DR, thus immediate referral to our Department was recommended. For patients with ungradable finding, referral to ophthalmologist for complete ophthalmologic examination in a few months was recommended. For patients with additional nondiabetic findings, referral to ophthalmologist for complete ophthalmologic examination as soon as possible or within a few months, according to diagnosis, was recommended.

After reviewing and grading retinal images, a report and follow-up or referral recommendation by the ophthalmologist was entered into patient medical records. A letter that included patient diagnosis and recommended follow-up time or referral recommendation was generated and mailed to patients.

The screening results for DR were analyzed, focused on diagnosis made, referral rates and follow-up recommendations in all DM patients screened, the subgroup of type $1 \mathrm{DM}$ patients and subgroup of newly diagnosed type 2 DM patients. Statistical descriptive analysis was carried out using IBM SPSS Statistics version 22.0 for Windows.

\section{Results}

A total of $1428 \mathrm{DM}$ patients were screened for DR in the twelve-month period and all 2856 eyes of these patients were included in this database review. The mean age of DM patients was 63.67 years (standard deviation (SD) 12.11); there were 840 (58.8\%) male and $588(41.2 \%)$ female patients. Of these $1428 \mathrm{DM}$ patients, $27(1.9 \%)$ were diagnosed with type $1 \mathrm{DM}$ and 1401 (98.1\%) with type $2 \mathrm{DM} ; 217(15.2 \%) \mathrm{pa}^{-}$ tients were only on diet therapy, $817(57.2 \%)$ received additional oral antidiabetic medication, and 394 (27.6\%) had additional insulin therapy. The mean duration of DM was 7.82 (SD 7.99) years in all DM patients. The mean VA was 0.78 (SD 0.24) in all 2856 eyes. Out of these 1428 DM patients, 1048 (73.4\%) were referred by their family physician and $380(26.6 \%)$ by a diabetologist. Out of these 1401 type $2 \mathrm{DM}_{\mathrm{pa}}-$ tients, $353(25.2 \%)$ had newly diagnosed type $2 \mathrm{DM}$.

Ungradable findings were recorded in $2.8 \%$ of all screened retinal photographs; $85.2 \%$ of all screened eyes were without DR. In $12 \%$ of all screened eyes, the presence of DR or CSME was recorded, as follows:
$6.9 \%$ of the eyes were graded as mild NPDR, $2.3 \%$ as moderate NPDR, $0.7 \%$ as severe NPDR, $0.6 \%$ as PDR and $1.5 \%$ as CSME. Accordingly, vision-threatening DR, which included severe NPDR, PDR and CSME, was found in $2.8 \%$ of all screened eyes. Additional nondiabetic clinical findings on retinal photographs were recorded in $5.2 \%$ of screened eyes, including age-related macular degeneration in $2.5 \%$, glaucoma suspect optic neuropathy in $0.6 \%$, cataract in $1.1 \%$, choroidal nevus in $0.7 \%$, and other nondiabetic causes of retinopathy (retinal vein occlusion, branch retinal vein occlusion) in $0.6 \%$ of cases.

Of all DM patients screened, 3.2\% were referred immediately to our Department because of visionthreatening DR and 9\% were referred to ophthalmologist for complete ophthalmologic examination because of ungradable retinal photographs or additional nondiabetic clinical findings, as soon as possible or in a few months, according to diagnosis.

The DM patient self-reported data on modifiable risk factors for DR, including hyperglycemia, hypertension, hyperlipidemia and obesity, were unreliable and insufficient and therefore not included in the analysis.

The subgroup of 54 eyes in 27 type $1 \mathrm{DM}$ patients were analyzed separately. The mean age of type $1 \mathrm{DM}$ patients was 30.04 (SD 10.31) years; there were 16 (59.3\%) female and $11(40.7 \%)$ male patients, and all were on insulin therapy. The mean duration of type 1 DM was 15.15 (SD 10.28) years. The mean VA was 0.93 (SD 0.12) in all 54 eyes. Out of these 27 type 1 DM patients, 12 (44.4\%) were referred by their family physician and $15(55.6 \%)$ by a diabetologist.

None of type $1 \mathrm{DM}$ screened retinal photographs was ungradable. In type $1 \mathrm{DM}$ group, $74.1 \%$ of screened eyes were without DR, while the presence of DR or CSME was recorded in $25.9 \%$ of screened eyes, as follows: $16.7 \%$ of eyes were graded as mild NPDR, $3.7 \%$ as moderate NPDR, $3.7 \%$ as PDR and $1.8 \%$ as CSME. Accordingly, vision-threatening DR, which included severe NPDR, PDR and CSME, was found in $5.5 \%$ of type $1 \mathrm{DM}$ screened eyes. Additional nondiabetic clinical finding of choroidal nevus on retinal photographs was recorded in $3.7 \%$ of screened type 1 DM eyes.

Of all type $1 \mathrm{DM}$ patients screened, $5.5 \%$ were referred immediately to our Department because of vision-threatening DR and 3.7\% were referred to ophthalmologist for complete ophthalmologic examina- 
tion because of additional nondiabetic clinical findings as soon as possible or in a few months, according to diagnosis.

The subgroup of 706 eyes in 353 newly diagnosed type $2 \mathrm{DM}$ patients were separately analyzed. The mean age of newly diagnosed type $2 \mathrm{DM}$ patients was 62.73 (SD 11.75) years; there were $212(60.1 \%)$ male and 141 (39.9\%) female patients; 127 (36.0\%) patients were only on diet therapy, $212(60.1 \%)$ received additional oral antidiabetic medication and 14 (4.0\%) had additional insulin therapy. The mean duration of newly diagnosed type $2 \mathrm{DM}$ was 0.52 (SD 0.13) years. The mean VA was 0.79 (SD 0.24) in all 706 eyes. Out of these 353 newly diagnosed type $2 \mathrm{DM}$ patients, 282 (79.9\%) were referred by their family physician and 71 (20.1\%) by a diabetologist.

Ungradable findings were recorded in $3.1 \%$ of newly diagnosed type $2 \mathrm{DM}$ screened retinal photographs; $92.5 \%$ of newly diagnosed type $2 \mathrm{DM}$ screened eyes were without DR; the presence of DR or CSME was recorded in $4.3 \%$ of newly diagnosed type $2 \mathrm{DM}$ screened eyes, as follows: $3.5 \%$ of eyes were graded as mild NPDR, $0.7 \%$ as moderate NPDR and $0.1 \%$ as CSME. Accordingly, vision-threatening DR including CSME was found in $0.1 \%$ of newly diagnosed type 2 DM screened eyes. Additional nondiabetic clinical findings on retinal photographs were found in $5.7 \%$ of newly diagnosed type $2 \mathrm{DM}$ eyes, i.e. age-related macular degeneration in $2.3 \%$, glaucoma suspect optic neuropathy in $0.3 \%$, cataract in $1.1 \%$, choroidal nevus in $1.0 \%$ and other nondiabetic causes of retinopathy (retinal vein occlusion, branch retinal vein occlusion) in $1.0 \%$ of cases.

Of all newly diagnosed type $2 \mathrm{DM}$ patients screened, $0.3 \%$ were referred immediately to our Department because of vision-threatening DR and 5.7\% were referred to ophthalmologist for complete ophthalmologic examination because of ungradable retinal photographs or additional nondiabetic clinical findings as soon as possible or in a few months, according to diagnosis.

\section{Discussion}

This study analyzed screening results on DR collected at Diabetic Retinopathy Screening Service Centre, Department of Ophthalmology, Maribor University Clinical Centre, Maribor, Slovenia in 2017, which was the second full year after launching the screening for DR program. Out of $1428 \mathrm{DM}$ patients screened in this study, $1.9 \%$ were diagnosed with type $1 \mathrm{DM}$ and $98.1 \%$ with type $2 \mathrm{DM}, 25.2 \%$ of these with newly diagnosed type 2 DM. Study results revealed $85.2 \%$ of all screened eyes to be without DR, $2.8 \%$ were ungradable and $12 \%$ had varying stages of DR. Vision-threatening DR was found in $2.8 \%$ and additional nondiabetic findings in $5.2 \%$ of all screened eyes, age-related macular degeneration in most of them. Of all DM patients screened, 3.2\% were referred immediately to our Department because of visionthreatening DR and 9\% were referred to ophthalmologist for complete ophthalmologic examination because of ungradable retinal photographs or additional nondiabetic clinical findings. In the group of type 1 DM, $74.1 \%$ of screened eyes were without DR and $25.9 \%$ were with varying stages of DR. In the same group, vision-threatening DR was found in 5.5\% and additional nondiabetic finding of choroidal nevus in $3.7 \%$ of screened eyes. Of all type $1 \mathrm{DM}$ patients screened, 5.5\% were referred immediately to our Department because of vision-threatening DR and 3.7\% were referred to ophthalmologist for complete ophthalmologic examination due to additional nondiabetic clinical findings. In the group of newly diagnosed type $2 \mathrm{DM}, 92.5 \%$ of screened eyes were without DR, $3.1 \%$ were ungradable and $4.3 \%$ were with varying stages of DR. In this group, vision-threatening DR was recorded in $0.1 \%$ and additional nondiabetic findings in $5.7 \%$ of screened eyes, most of them with agerelated macular degeneration. Of all newly diagnosed type $2 \mathrm{DM}$ patients screened, $0.3 \%$ were referred immediately to our Department due to vision-threatening DR and 5.7\% were referred to ophthalmologist for complete ophthalmologic examination because of ungradable retinal photographs or additional nondiabetic clinical findings.

Schellini et al. report on the presence of DR of varying and undefined stages in $7.6 \%$ of 407 screened self-reported type $2 \mathrm{DM}$ patients with mean age of 58.8 years and unknown duration of $\mathrm{DM}^{18}$. In our study, $12 \%$ of all screened eyes in $1428 \mathrm{DM}$ patients showed varying stages of $\mathrm{DR}$, which could be ascribed to the fact that we included type $1 \mathrm{DM}$ and type 2 DM patients with higher mean age of 63.7 years and longer duration of DM in comparison to the above mentioned study. 
In the Gutenberg Health Study, the weighted prevalence of DR in newly diagnosed screening-detected type $2 \mathrm{DM}$ was $13 \%$; out of 285 newly diagnosed screening-detected type $2 \mathrm{DM}$ patients, $12 \%$ had mild NPDR, $0.6 \%$ moderate NPDR and $0.3 \%$ PDR, with no cases of severe NPDR or diabetic maculopathy ${ }^{19}$. The Hoorn Screening Study found a higher prevalence of DR in screening-detected type $2 \mathrm{DM}$ of $7.6 \%$ as compared to $1.9 \%$ in those with newly diagnosed type $2 \mathrm{DM}$ in general practice ${ }^{20}$. In our study, $80 \%$ of 353 newly diagnosed type $2 \mathrm{DM}$ patients were referred for screening for DR by their family physician and $20 \%$ by a diabetologist; the presence of DR or CSME was found in $4.3 \%$, including mild NPDR in $3.5 \%$, moderate NPDR in $0.7 \%$ and CSME in $0.1 \%$ of the screened eyes.

Papavasileiou et al. in their retrospective twelvemonth database review of systematic DR screening in $15196 \mathrm{DM}$ patients found referable vision-threatening DR in $4.94 \%$ of patients ${ }^{21}$. In contrast, in our study that included less DM patients, referable visionthreatening DR was found in $2.8 \%$ of all screened eyes in $1428 \mathrm{DM}$ patients.

Tsui et al. provided a snapshot of teleretinal screening for DR in $120 \mathrm{DM}$ patients and report that 15\% had varying stages of NPDR, no PDR was found, 5\% were ungradable images, $13.3 \%$ were glaucoma suspect and $10.0 \%$ had age-related macular degeneration; $55.8 \%$ of screened DM patients were referred to an eye department for further ophthalmic evaluation, including any level of DR and any other additional nondiabetic clinical finding ${ }^{22}$. In our study, varying stages of DR were recorded in $12 \%$ of all screened eyes of 1428 DM patients; $6.9 \%$ of eyes had mild NPDR, $2.3 \%$ moderate NPDR, $0.7 \%$ severe NPDR, $0.6 \%$ had PDR and $1.5 \%$ had CSME. In our study, $2.8 \%$ of screened images were ungradable and additional nondiabetic findings were detected in $5.2 \%$ of the screened eyes. In our study, $3.2 \%$ of all DM patients screened were referred immediately to our Department because of vision-threatening DR and 9\% were referred to ophthalmologist for complete ophthalmologic examination due to ungradable retinal photographs or additional nondiabetic clinical findings.

The main strength of this study was a relatively large sample size, above all newly diagnosed type 2 DM patients. All DM patients were also screened by a standardized protocol of digital retinal photography evaluated for the presence and stage of DR or CSME and subsequently graded by an ophthalmologist. Therefore, additional nondiabetic clinical findings on retinal photographs could also be detected by the ophthalmologist, who recommended follow-up time, referral for further ophthalmic evaluation according to diagnosis, or referral to our Department for further treatment when vision-threatening DR was detected. Unfortunately, only limited information was available on the major modifiable risk factors for DR. We could not obtain measures of glycemic control, blood pressure, lipid concentration and body mass index. The patient self-reported data on these risk factors were unreliable and insufficient. Wang et al. report on a surprisingly small number of DM patients with DR, less than $50 \%$, who were aware of the importance of glycosylated hemoglobin, only $17 \%$ understood its ideal level, significance and physiology, although younger age and postsecondary education were significantly associated with due understanding of glycosylated hemoglobin ${ }^{23}$. Therefore, public education by family physician, diabetologist or ophthalmologist on DM and prevention of associated complications including DR is important. It is estimated that in developing countries, half of DM patients do not undergo fundus examination at least once a year ${ }^{24}$. Family physicians and diabetologists must be informed and educated by ophthalmologists on the current DR screening and referral guidelines to ensure early detection and prompt intervention for DM patients with vision-threatening DR. The study by Schoenfeld et al. found that more than one-third of DM patients do not follow the standard screening guidelines ${ }^{25}$. Thus, education is crucial to prevent $\mathrm{DM}$ and $\mathrm{DR}$.

In conclusion, in this study, a small proportion of screened DM patients with detected DR had visionthreatening DR, demonstrating that screening for DR enables early detection and prompt treatment of DM related visual impairment.

\section{References}

1. Wild S, Roglic G, Green A, Sicree R, King H. Global prevalence of diabetes: estimates fort the year 2000 and projections for 2030. Diabetes Care. 2004;27:1047-53, doi: 10.2337/diacare.27.5.1047.

2. Guariguata L, Whiting DR, Hambleton I, Beagley J, Linnenkamp U, Shaw JE. Global estimates of diabetes prevalence for 2013 and projections for 2035. Diabetes Res Clin Pract. 2014; 103:137-49, doi: 10.1016/j.diabres.2013.11.002. 
3. Antonetti DA, Klein R, Gardner TW. Diabetic retinopathy. N Engl J Med. 2012;366:1227-39, doi: 10.1056/NEJMra 1005073 .

4. Zhang X, Saadine JB, Chou CF, Cotch MF, Cheng YJ, Geiss LS, et al. Prevalence of diabetic retinopathy in the United States, 2005-2010. JAMA. 2010;304:649-56, doi: 10.1001/ jama.2010.1111.

5. Leasher JL, Bourne RR, Flaxman SR, Jonas JB, Keeffe J, Naidoo N, et al. Global estimates on the number of people blind or visually impaired by diabetic retinopathy: a meta-analysis from 1990 to 2010. Diabetes Care. 2016;39:1643-9, doi: 10.2337/ dc15-2171.

6. Arun CS, Al-Bermani A, Stannard K, Taylor R. Long-term impact of retinal screening on significant diabetes-related visual impairment in the working age population. Diabet Med. 2009;26:489-92, doi: 10.1111/j.1464-5491.2009.02718.x.

7. American Diabetes Association. Standards of medical care in diabetes - 2011. Diabetes Care. 2011;34(Suppl 1):S11-61, doi: 10.2337/dc11-S011

8. Jacobson AM, Braffett BH, Cieary PA, Gubitosi-Klug RA, Larkin ME; DCCT/EDIC Research Group. The long-term effects of type 1 diabetes treatment and complications on health-related quality of life. A 23-year follow-up of the Diabetes Control and Complications/Epidemiology of Diabetes Interventions and Complications cohort. Diabetes Care. 2013;36:3131-8, doi: 10.2337/dc12-2109.

9. Early Treatment Diabetic Retinopathy Study Research Group. Grading diabetic retinopathy from stereoscopic color fundus photographs - an extension of the modified Airlie House classification. ETDRS report number 10. Early Treatment Diabetic Retinopathy Study Research Group. Ophthalmology. 1991;98:786-806.

10. Forster AS, Forbes A, Dodhia H, Connor C, Du Chemin A, Sivaprasad S, et al. Non-attendance at diabetic eye screening and risk of sight-threatening diabetic retinopathy: a population-based cohort study. Diabetologia. 2013;56:2187-93, doi: 10.1007/s00125-013-2975-0.

11. Burger W, Hovener G, Dusterhus R, Hartmenn R, Weber B. Prevalence and development of retinopathy in children and adolescents with type 1 (insulin-dependent) diabetes mellitus. A longitudinal study. Diabetologia. 1986;29:17-22, doi: 10.1007/BF02427275.

12. Jones CD, Greenwood RH, Misra A, Bachmann MO. Incidence and progression of diabetic retinopathy during 17 years of a population-based screening program in England. Diabetes Care. 2012;35:592-6, doi: 10.2337/dc11-0943.

13. Porta M, Maurino M, Severini S, Lamarmora E, Trento M, Sitia E, et al. Clinical characteristics influence screening intervals for diabetic retinopathy. Diabetologia. 2013;56:2147-52, doi: 10.1007/s00125-013-2989-7.
14. Folk JC, Adelman RA, Flaxel CJ, Hyman L, Pulido JS, Olsen TW. Retina vitreous preferred practice pattern. Diabetic retinopathy. Am Acad Ophthalmol. 2016;1-58.

15. Rosenberg JB, Tsui I. Screening for diabetic retinopathy. N Engl J Med. 2017;376:1587-8, doi: 10.1056/NEJMe1701820

16. The DCCT/EDIC Research Group. Frequency of evidencebased screening for retinopathy in type 1 diabetes. N Engl J Med. 2017;376:1507-16, doi: 10.1056/NEJMoa1612836

17. Javitt JC, Aiello LP, Chiang Y, Ferris FL III, Canner JK, Greenfield S. Preventive eye care in people with diabetes is cost-saving to the federal government: implication for health care reform. Diabetes Care. 1994;17:909-17, doi: 10.2337/diacare.17.8.909.

18. Schellini SA, Carvalho GM, Rendiero FS, Padovani CR, Hirai FE. Prevalence of diabetes and diabetic retinopathy in a Brazilian population. Ophthalmic Epidemiol. 2014;21:33-8, doi: 10.3109/09286586.2013.868004.

19. Ponto KA, Koenig J, Peto T, Lamparter J, Raum P, Wild PS, et al. Prevalence of diabetic retinopathy in screening-detected diabetes mellitus: results from the Gutenberg Health Study (GHS). Diabetologia. 2016;59:1913-9, doi: 10.1007/s00125016-4013-5.

20. Spijkerman AM, Dekker JM, Nijpels G, Kostense PJ, Kors JA, Ruwaard D, et al. Microvascular complications at time of diagnosis of type 2 diabetes are similar among diabetic patients detected by targeted screening and patients newly diagnosed in general practice: the Hoorn Screening Study. Diabetes Care. 2003;26:2604-8, doi: 10.2337/diacare.26.9.2604..

21. Papavasileiou E, Dereklis D, Oikonomidis P, Grixti A, Kumar BV, Prased S. An effective programme to systematic diabetic retinopathy screening in order to reduce diabetic retinopathy blindness. Hell J Nucl Med. 2014;17(Suppl 1):30-4.

22. Tsui I, Havunjian MA, Davis JA, Giaconi JA. Snapshot of teleretinal screening for diabetic retinopathy at the West Los Angeles Medical Center. Telemed J E Health. 2016;22:843-6, doi: 10.1089/tmj.2015.0246.

23. Wang S, Tikellis G, Wong N, Wong TY, Wang JJ. Lack of knowledge of glycosylated hemoglobin in patients with diabetic retinopathy. Diabetes Res Clin Pract. 2008;81:315-7, doi: 10.1016/j.diabres.2008.03.011.

24. Rani PK, Raman R, Sharma V, Mahuli SV, Tarigopala A, Sudhir RR, et al. Analysis of a comprehensive diabetic retinopathy screening model for rural and urban diabetics in developing countries. Br J Ophthalmol. 2007;91:1425-9, doi: 10.1136/ bjo.2007.120659.

25. Schoenfeld ER, Greene JM, Wu SY, Leske MC. Patterns of adherence to diabetes vision care guidelines: baseline findings from the Diabetic Retinopathy Awareness Program. Ophthalmology. 2001;108:563-71, doi: 10.1016/s0161-6420(00)00600-x. 


\section{Sažetak \\ PRIKAZ REZULTATA DVANAESTOMJESEČNOG PROBIRA NA DIJABETIČKU RETINOPATIJU}

\section{T. Gračner}

Cilj je prikazati rezultate analize dvanaestomjesečne baze podataka probira na dijabetičku retinopatiju (DR). U retrospektivnoj studiji analizirano je 1428 bolesnika s dijabetesom melitusom (DM) pregledanih tijekom 2017. godine. Oftalmolog je pregledao snimke očne pozadine na prisutnost i stupanj DR te na prisutnost drugih nedijabetičkih promjena. Primijenjen je sljedeći sustav stupnjevanja DR: bez DR, blaga neproliferativna DR (NPDR), umjerena NPDR, teška NPDR, proliferativna DR (PDR), klinički značajan makularni edem (clinically significant macular edema, CSME) te nerazvrstani. Teška NPDR, PDR i CSME razvrstani su kao za vid ugrožavajuća DR. Od 1428 bolesnika s DM, 27 ih je imalo DM tip 1,1401 DM tip 2, od potonjih je 353 imalo novootkriveni DM tip 2. Od svih pregledanih očiju 85,2\% ih je bilo bez DR, 2,8\% nerazvrstanih, $12 \%$ je imalo različite stupnjeve DR. Kod 2,8\% svih pregledanih očiju nađena je za vid ugrožavajuća DR, u $5,2 \%$ nađene su dodatne nedijabetičke promjene. Bez DR je bilo 92,5\% očiju novootkrivenih dijabetičara s DM tipa 2, 3,1\% je bilo nerazvrstanih, 4,3\% je imalo različite stupnjeve DR. Kod 0,1\% očiju novootkrivenih dijabetičara s DM tipa 2 nađena je za vid ugrožavajuča DR, a u 5,7\% nađene su dodatne nedijabetičke promjene. U zaključku, mali udio pregledanih dijabetičara s otkrivenom DR imao je za vid ugrožavajuću DR.

Ključne riječi: Dijabetes melitus; Dijabetička retinopatija; Probir; Proliferationa retinopatija; Makulopatija 